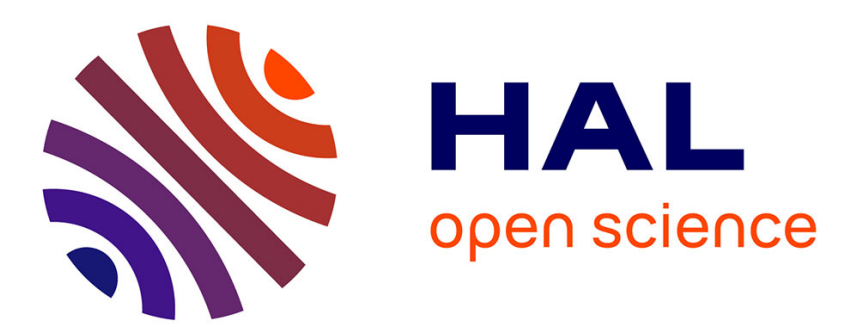

\title{
Thermal oxidation of epoxies: Influence of diamine hardener
}

Esteve Ernault, Emmanuel Richaud, Bruno Fayolle

\section{To cite this version:}

Esteve Ernault, Emmanuel Richaud, Bruno Fayolle. Thermal oxidation of epoxies: Influence of diamine hardener. Polymer Degradation and Stability, 2016, 134, pp.76-86. 10.1016/j.polymdegradstab.2016.09.030 . hal-01473986

\section{HAL Id: hal-01473986 \\ https://hal.science/hal-01473986}

Submitted on 22 Feb 2017

HAL is a multi-disciplinary open access archive for the deposit and dissemination of scientific research documents, whether they are published or not. The documents may come from teaching and research institutions in France or abroad, or from public or private research centers.
L'archive ouverte pluridisciplinaire $\mathbf{H A L}$, est destinée au dépôt et à la diffusion de documents scientifiques de niveau recherche, publiés ou non, émanant des établissements d'enseignement et de recherche français ou étrangers, des laboratoires publics ou privés. 


\title{
Thermal oxidation of epoxies: Influence of diamine hardener
}

\author{
Esteve Ernault, Emmanuel Richaud*, Bruno Fayolle \\ PIMM UMR 8006, Arts et Métiers ParisTech, CNRS, CNAM, 151 bd de l'Hôpital, Paris, France
}

\section{A R T I C L E I N F O}

Article history:Received 19 July

2016

Received in revised form

5 September 2016

Accepted 26 September 2016

Available online 28 September 2016

Keywords:

Epoxy/diamine

Thermal oxidation

Chain scissions

Crosslinking

\begin{abstract}
A B S T R A C T
This work reports the thermal oxidation of DGEBA resins totally cured with cycloaliphatic (isophorone diamine) or with linear aliphatic (trioxa-tridecanediamine or TTDA) diamine hardener. Chemical changes (carbonyl build-up) were monitored by FTIR and macromolecular changes (chains scission and crosslinking) from $T_{g}$ variations measured by DSC. Exposition at several temperatures and under several oxygen pressures showed that DGEBA/IPDA has systematically the highest oxidation rate. It was also observed that DGEBA/IPDA undergoes mainly chain scissions whereas DGEBA/TTDA undergoes a predominant crosslinking under air being partially suppressed under enhanced oxygen pressure. Results were discussed on the basis of the possible influence of the structure of hardener.
\end{abstract}

\section{Introduction}

Epoxy resins are commonly used for coatings, matrices for composite materials or adhesives. There is a wide variety of prepolymer/hardener pairs adapted for each sort of process (laminating, prepreg, injection, hand lay-up...) that lead to thermosets with elevated mechanical properties (modulus ca $3 \mathrm{GPa}$, flexural strength ca $125 \mathrm{MPa}$ ) and electrical insulating properties. It is however known that epoxys are sensitive to thermal oxidation which can limit their long term use [1-5].

Oxidation of epoxy/diamine systems has been covered by several papers (see for example [6-10]), the main conclusions are of which:

(I) Thermal-oxidation of epoxies follows a general autoxidation mechanism in which the main source of radicals is the decomposition of hydroperoxides [7,11]. Even though oxidation can be described by classical kinetic models, it is not clear if the kinetic parameters associated to elementary reactions are common to all epoxy resins or not.

(II) Among the main molecular modifications, the appearance of several sort of amide and carbonyl species was shown by FTIR $[6,9,12]$. It seems that they originate from isopropanol groups being systematically involved in radical attack.

(III) The changes at macromolecular scale during thermooxidation have been investigated by $T_{g}$ change (measured

\footnotetext{
* Corresponding author

E-mail address: emmanuel.richaud@ensam.eu (E. Richaud).
}

by Differential Scanning Calorimetry) or $\mathrm{T}_{\alpha}$ (measured by Dynamic Mechanical Analysis). In aromatic epoxies, a decrease of $\mathrm{T}_{\alpha}$ is attributed to a predominant chain scission phenomenon $[13,14]$. The so called "internal antiplastification" $[13,15]$ is also observed and would come from the destruction of isopropanol moiety associated to $\beta$ transition [16].

Since there is, to our knowledge, no definitive conclusion on the link between structure, oxidizability and consequences of oxidation on thermo-mechanical properties, the aim of this work is to study the thermal oxidation of DGEBA/isophorone diamine (IPDA) and DGEBA/4,7,10-Trioxa-1,13-tridecanediamine (TTDA). By comparing the degradation of these two systems, we aim to answer the following questions:

- Are chemical changes observed in both these epoxy systems similar to those already reported in the literature?

- What is the influence of molecular mobility on oxidation kinetics, knowing $\mathrm{T}_{\mathrm{g}}$ of the two chosen systems is quite different?

- What is the influence of the hardener part on the thermooxidation of epoxy/amine?

\section{Experimental}

\subsection{Materials}

The bisphenol A diglycidyl ether DGEBA (DER 332 - CAS 1675- 
54-3 - ref 31185 supplied by Sigma Aldrich) has a degree of polymerization $\mathrm{n}=0$ and a number average molecular mass equal to $340 \mathrm{~g} / \mathrm{mol}$. Two kinds of hardeners have been chosen:

- the isophorone diamine here denoted by IPDA (CAS 2855-13-2 ref 118184 supplied by Sigma Aldrich, $M=170.3 \mathrm{~g} / \mathrm{mol}$ ).

- the 4,7,10-trioxa-1,13-tridecanediamine here denoted by TTDA (CAS 4246-51-9 - ref 369519 supplied by Sigma Aldrich, $\mathrm{M}=220.3 \mathrm{~g} / \mathrm{mol})$.

The structure of chemicals is given in Fig. 1.

These components were mixed in stoichiometric ratio i.e. $100 \mathrm{~g}$ of DER $332+25 \mathrm{~g}$ IPDA and $100 \mathrm{~g}$ DER $332+29 \mathrm{~g}$ of TTDA. DSC scans of those mixtures display the classical exothermal peak with a specific cure enthalpy ca $400 \mathrm{~J} / \mathrm{g}$ for both systems respectively and a maximal temperature of $117{ }^{\circ} \mathrm{C}$ for DGEBA/IPDA (consistently with $[17,18]$ ) and $114{ }^{\circ} \mathrm{C}$ for DGEBA/TTDA.

The systems were fully cured (as checked by DSC from the total disappearance of exothermal signal and by FTIR from the loss of $914 \mathrm{~cm}^{-1}$ peak attributed to epoxide group) according the following conditions:

- curing at $60{ }^{\circ} \mathrm{C}$ during $2 \mathrm{~h}$ and post curing at $160{ }^{\circ} \mathrm{C}$ under vacuum for $2 \mathrm{~h}$ for DGEBA/IPDA

- curing at $60^{\circ} \mathrm{C}$ during $1 \mathrm{~h}$ and post curing at $80^{\circ} \mathrm{C}$ under vacuum for $2 \mathrm{~h}$ for DGEBA/TTDA.

In order to obtain $10-30 \mu \mathrm{m}$ films so as to avoid the so-called Diffusion Limited Oxidation [3-5]. The glass transition temperatures of the networks were found to be ca $166^{\circ} \mathrm{C}$ for DGEBA/IPDA and $69{ }^{\circ} \mathrm{C}$ for DGEBA/TTDA. Their DSC thermograms (Fig. 12) are shown in Appendix and confirm they are fully cured.

\subsection{Ageing}

Thermal ageing under atmospheric air was performed in ventilated ovens (calibrated at $\pm 3^{\circ} \mathrm{C}$ ) at $110^{\circ} \mathrm{C}, 150{ }^{\circ} \mathrm{C}$ and $200^{\circ} \mathrm{C}$. Films were periodically removed for analysis.

The influence of oxygen pressure on oxidation rate was studied by performing ageing tests in autoclaves under 50 bars of pure oxygen at $110^{\circ} \mathrm{C}$.

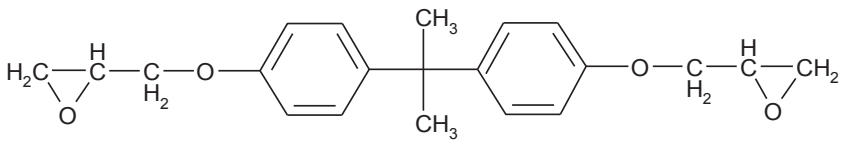

(a)<smiles>CC1(C)CC(N)CC(C)(CN)C1</smiles>

(b)<smiles>NCCCOCCOCCOCCCN</smiles>

(c)

Fig. 1. Chemical structure of (a) bisphenol A diglycidyl ether (DGEBA), (b) isophorone diamine (IPDA) (c) 4,7,10-Trioxa-1,13-tridecanediamine (TTDA).

\subsection{Fourier transform infra-red spectroscopy (FTIR)}

FTIR spectroscopy in transmission mode was performed on free standing films using a Frontier spectrophotometer (PerkinElmer) in the 550 to $4000 \mathrm{~cm}^{-1}$ wavenumber range by averaging 16 scans with a $4 \mathrm{~cm}^{-1}$ resolution. Spectra were interpreted using the Spectrum software (PerkinElmer) in order to determine the absorbance value from which the concentration of oxidation products was calculated with the Beer Lambert law:

$A=\varepsilon_{\lambda} \times l \times C_{\lambda}$

A being the absorbance (corrected by the baseline value), $\varepsilon_{\lambda}$ (1/ $\mathrm{mol} / \mathrm{cm}$ ) being the molar absorptivity taken equal to $\varepsilon_{1660}=470 \mathrm{l} /$ $\mathrm{mol} / \mathrm{cm}$ for amides [9], and $\varepsilon_{1730}=350 \mathrm{l} / \mathrm{mol} / \mathrm{cm}$ for carbonyls [19], 1 $(\mathrm{cm})$ the thickness of the film and $\mathrm{C}_{\lambda}(\mathrm{mol} / \mathrm{l})$ the concentration of the considered species.

\subsection{Differential scanning calorimetry (DSC)}

Differential scanning calorimetry measurements were made with a DSC Q1000 (TA Instruments). Samples with mass ranging between 3 and $5 \mathrm{mg}$ and sealed in aluminum pans were heated from $0{ }^{\circ} \mathrm{C}$ to $250{ }^{\circ} \mathrm{C}$ at a $10{ }^{\circ} \mathrm{C} / \mathrm{min}$ ramp under nitrogen flow $(50 \mathrm{ml} / \mathrm{min})$. Results were interpreted using TA Analysis software. DSC analyses were done to check the total cure of samples and to measure the value of the glass transition temperature of aged samples. $T_{g}$ values were measured during the second heating ramp (i.e. after having removed the thermal history of samples). Two samples of the same resin have been analyzed for each exposure time to control measurements reproducibility.

\section{Results}

\subsection{Effect of temperature on the stable oxidation products formation}

The main changes induced by thermal oxidation are detected in the $1550-1850 \mathrm{~cm}^{-1}$ wavenumber range for both systems (Fig. 2). An increase of $1656 \mathrm{~cm}^{-1}$ peak is observed in DGEBA/IPDA as well as in DGEBA/TTDA. This peak is associated with the appearance of amide groups $[6,9,12,20]$. A band grows around $1725 \mathrm{~cm}^{-1}$ for DGEBA/IPDA and around $1736 \mathrm{~cm}^{-1}$ for DGEBA/TTDA. These bands are usually attributed to the vibration of carbonyl groups. Mechanisms responsible for the formation of oxidative products will be discussed in the next section.

The concentrations in each kind of oxidation products were assessed from Beer Lambert law and their changes were plotted versus time for each exposure conditions (Fig. 3, where the arrows correspond to the time at which samples cannot be handed anymore).

From Fig. 3, the following comments can be drawn:

- No significant induction period is witnessed for both systems whatever the exposure temperature, as commonly observed for comparable systems $[9,21]$. Oxidation rate is defined as the highest slope of each curve. At $150{ }^{\circ} \mathrm{C}$ and $200{ }^{\circ} \mathrm{C}$, the maximal oxidation rate is equal to the initial rate whereas a slight auto acceleration is noticed at $110{ }^{\circ} \mathrm{C}$ and is more visible on DGEBA/ IPDA system.

- Oxidation rate values are reported in Table 1. It appears that the oxidation rate for amide groups formation is always equal or 

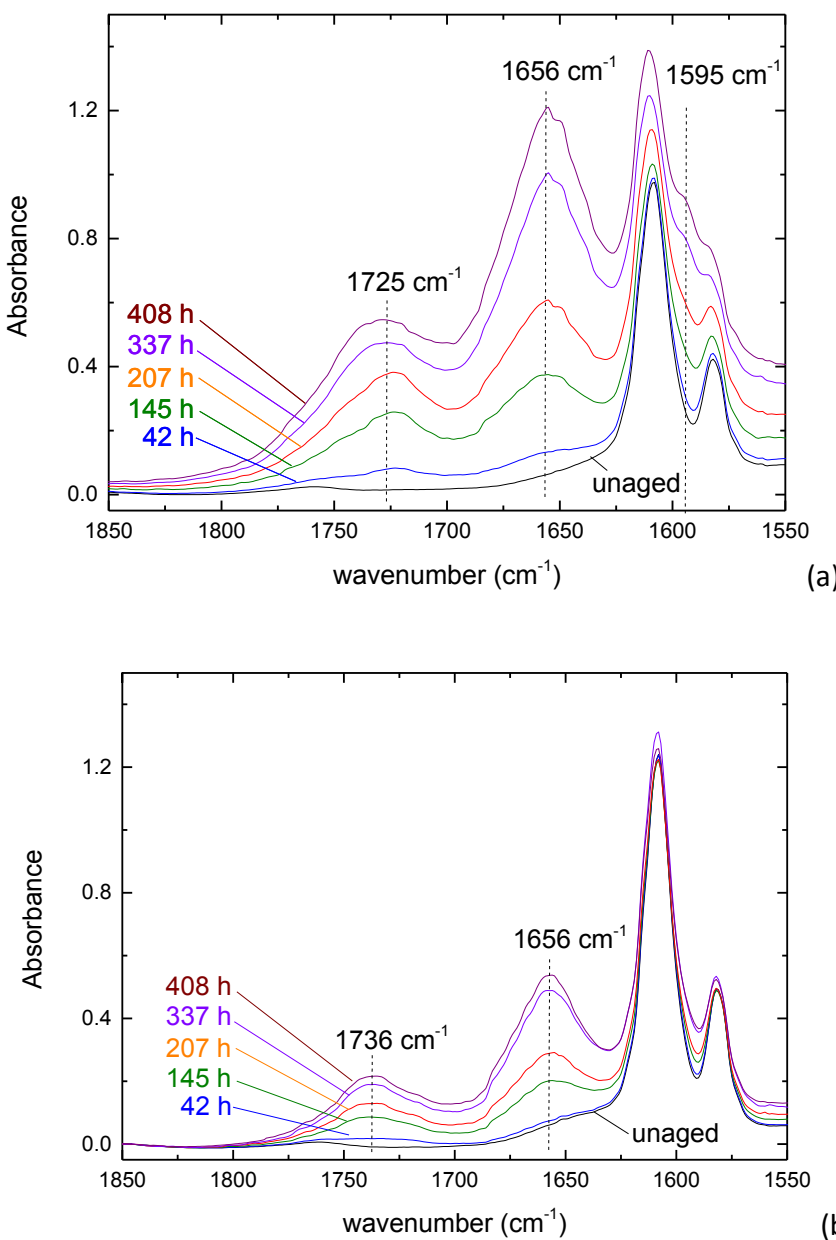

(b)

Fig. 2. FTIR spectra of DGEBA/IPDA (a) and DGEBA/TTDA (b) during oxidative thermal ageing at $110^{\circ} \mathrm{C}$.

higher than oxidation rate for carbonyl groups formation whatever the considered epoxy system for a given exposure condition (this result depends, in part, on the choice of values for molar absorptivity for amides and carbonyls which were chosen in the range of acceptable values). Furthermore, the rate of carbonyl and amide formation is always higher for DGEBA/ IPDA than for DGEBA/TTDA.

- The concentration in oxidation product reaches a plateau for the long exposure times especially at high temperatures (150 and $200^{\circ} \mathrm{C}$ ). There are several explanations for this behavior: partial substrate consumption [22], loss of low molecular weight volatile compounds containing carbonyl and amide groups [11,23] (NB: the mass loss value at the long exposure times becomes higher than $5 \%$, but it was considered as sufficiently low in the low exposure times so as to the maximal oxidation rates values given in Table 1 can be considered as reliable), asymptotic or steady state concentration in hydroperoxides close to 0 [24] but the validation of the best scenario would be based, in our mind, on a relevant kinetic model, which is out of the scope of the present paper.

Values of oxidation rates were plotted in Fig. 4. It appears the data follow an Arrhenius behavior. Apparent activation energies of oxidation rate for amides and carbonyls formation are very close $(\sim 83 \pm 5 \mathrm{~kJ} / \mathrm{mol})$, which is consistent with DGEBA/PAA and DGEBA/POPA132 [25] (despite activation energies are slightly lower).

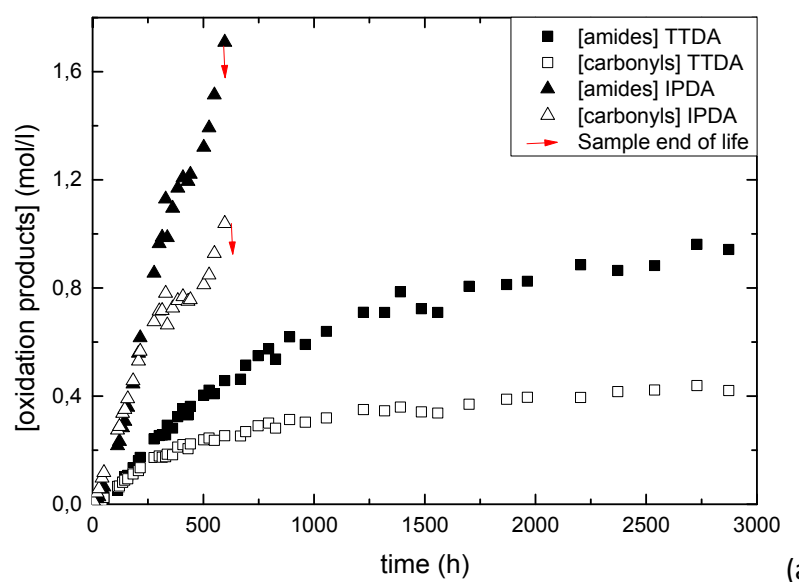

(a)



(b)

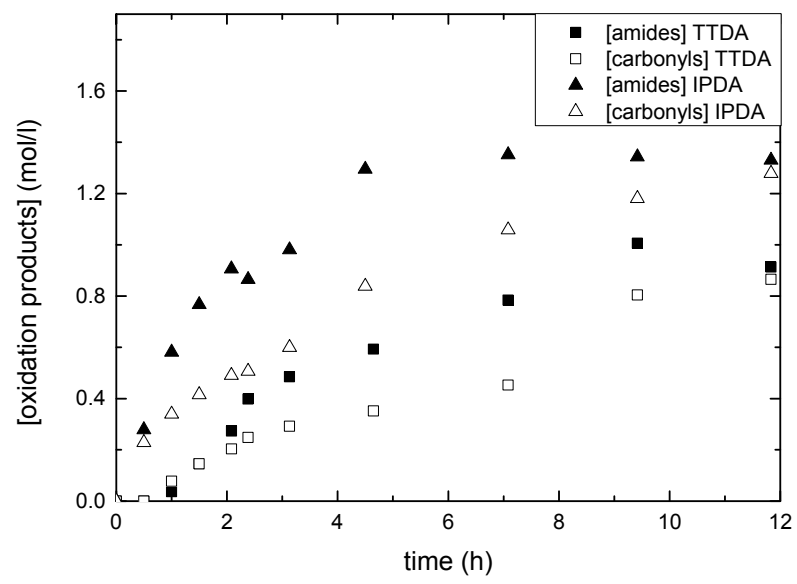

(c)

Fig. 3. Changes in concentration of amides and carbonyls under air at $110^{\circ} \mathrm{C}(\mathrm{a}), 150{ }^{\circ} \mathrm{C}$ (b) and $200{ }^{\circ} \mathrm{C}(\mathrm{c})$.

\subsection{Effect of oxygen pressure on stable oxidation products formation}

The influence of oxygen pressure on oxidation kinetics of DGEBA/IPDA and of DGEBA/TTDA has been investigated at $110^{\circ} \mathrm{C}$. Fig. 5 shows infrared spectra obtained for both systems at $110{ }^{\circ} \mathrm{C}$ under 50 bars of oxygen, at which we expect to be close to the "oxygen excess regime" i.e. where termination reaction involving alkyl radicals $\mathrm{P}^{\circ}\left(\mathrm{P}^{\circ}+\mathrm{P}^{\circ} \rightarrow\right.$ inactive products, and 
Table 1

Oxidation rate of amides and carbonyls build up in air at $110^{\circ} \mathrm{C}, 150{ }^{\circ} \mathrm{C}, 200{ }^{\circ} \mathrm{C}$.

\begin{tabular}{lcc}
\hline System & DGEBA $/$ IPDA & DGEBA/TTDA \\
\hline Oxidation rate of amides formation in air & \\
$\mathrm{r}_{\mathrm{ox}} 110^{\circ} \mathrm{C}(\mathrm{mol} / \mathrm{l} / \mathrm{s})$ & $1.1 \mathrm{E}-06$ & $3.1 \mathrm{E}-07$ \\
$\mathrm{r}_{\mathrm{ox}} 150^{\circ} \mathrm{C}(\mathrm{mol} / \mathrm{l} / \mathrm{s})$ & $9.5 \mathrm{E}-06$ & $3.1 \mathrm{E}-06$ \\
$\mathrm{r}_{\mathrm{ox}} 200^{\circ} \mathrm{C}(\mathrm{mol} / \mathrm{l} / \mathrm{s})$ & $1.6 \mathrm{E}-04$ & $4.9 \mathrm{E}-05$ \\
Oxidation rate of carbonyls formation in air & \\
$\mathrm{r}_{\mathrm{ox}} 110^{\circ} \mathrm{C}(\mathrm{mol} / \mathrm{l} / \mathrm{s})$ & $7.7 \mathrm{E}-07$ & $1.9 \mathrm{E}-07$ \\
$\mathrm{r}_{\mathrm{ox}} 150^{\circ} \mathrm{C}(\mathrm{mol} / \mathrm{l} / \mathrm{s})$ & $3.6 \mathrm{E}-06$ & $1.6 \mathrm{E}-06$ \\
$\mathrm{r}_{\mathrm{ox}} 200^{\circ} \mathrm{C}(\mathrm{mol} / \mathrm{l} / \mathrm{s})$ & $9.4 \mathrm{E}-05$ & $3.8 \mathrm{E}-05$ \\
\hline
\end{tabular}

$\mathrm{P}^{\circ}+\mathrm{POO}^{\circ} \rightarrow$ inactive products) are negligible compared to termination process involving peroxy radicals $\mathrm{POO}^{\circ}$ $\left(\mathrm{POO}^{\circ}+\mathrm{POO}^{\circ} \rightarrow\right.$ inactive products) $[26]$.

It is noteworthy that the same absorption peaks appear for exposure under 50 bars of oxygen and under air. We will hence assume that amides and carbonyls can be used as common tracers to discuss on the dependence of oxidation rates on oxygen pressure.

Kinetics of oxidation products build up at $110{ }^{\circ} \mathrm{C}$ under air and under 50 bars of oxygen are compared in Fig. 6. For DGEBA/IPDA system under high oxygen pressure, it seems that amides and carbonyls concentrations have the same order of magnitude. However, in the case of the DGEBA/TTDA system under 50 bars of oxygen, one can notice that carbonyls concentration is higher than amides concentration at low conversion degree i.e. for carbonyl concentration below $0.2 \mathrm{~mol} / \mathrm{l}$. This point will be discussed later.

We were interested in plotting carbonyls vs amides concentration for all the exposure conditions studied here (Fig. 7):

- First, the ratio carbonyl/amide is almost constant for both systems in a first approach (this result is here clearly independent of the choice made for molar absorptivity value).

- For the DGEBA/TTDA system, the proportion of carbonyls over amides is higher under oxygen pressure than under air. This phenomenon can be attributed to a specific source of carbonyl linked to TTDA segment oxidation (see "Discussion" section).

- For both systems, a slight curvature is observed when the amide concentration excesses ca $0.2 \mathrm{~mol} / \mathrm{l}$. A first explanation is that a significant mass loss occurs and volatiles would contain mostly carbonyl groups but this interpretation remains speculative in the absence of characterization of evolved volatile compounds.



Fig. 4. Arrhenius plot of oxidation rate for DGEBA/IPDA and DGEBA/TTDA under air and activation energies of oxidation $\left(\mathrm{E}_{\mathrm{ox}}\right)$.

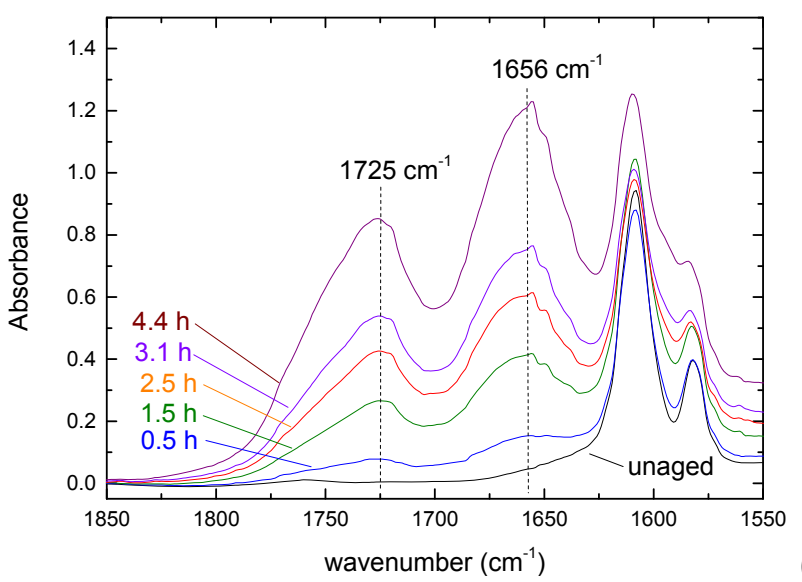

(a)

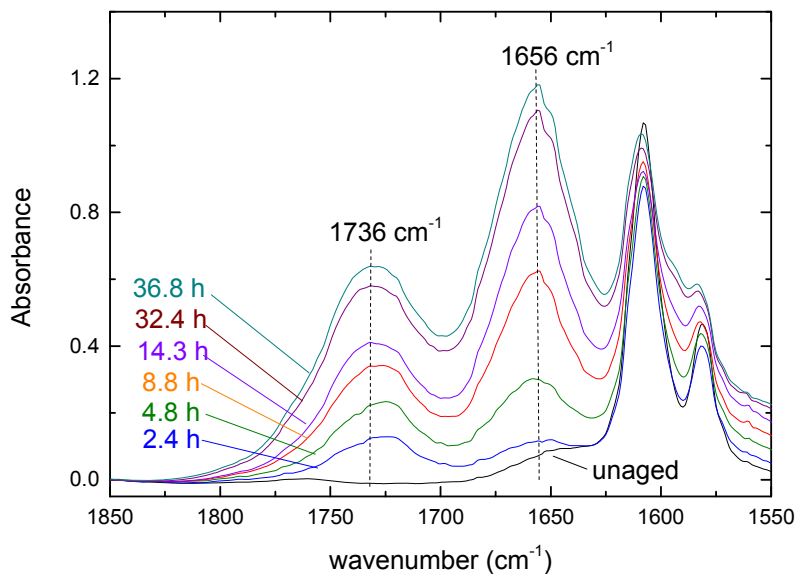

(b)

Fig. 5. FTIR spectra of DGEBA/IPDA (a) and DGEBA/TTDA (b) during oxidative thermal ageing at $110^{\circ} \mathrm{C}$ under 50 bars of oxygen.

\subsection{Changes at macromolecular scale}

Values of glass transition temperature $\left(\mathrm{T}_{\mathrm{g}}\right)$ have been measured during the exposures at $110^{\circ} \mathrm{C}$ under atmospheric air and 50 bars of oxygen. They are reported in Fig. 8.

For the DGEBA/IPDA system, a significant decrease of $T_{g}$ is observed either in air environment and under 50 bars of oxygen. No further measurements have been done on DGEBA/IPDA films after $544 \mathrm{~h}$ in air and $5.5 \mathrm{~h}$ under oxygen, because samples were too damaged. It is noticeable that DGEBA/IPDA is in glassy state at the beginning of the exposure, and later in rubbery state since $T_{g}$ reaches a value below $110^{\circ} \mathrm{C}$ after $3.5 \mathrm{~h}$ under oxygen and $544 \mathrm{~h}$ in air. This large $T_{g}$ decrease indicates that molecular mobility increases during oxidation and that oxidation leads to a chain scission process predominating over a possible crosslinking process in the case of the DGEBA/IPDA system whatever the oxygen concentration.

For the DGEBA/TTDA system, $T_{g}$ increases in air environment whereas $T_{g}$ is almost constant at 50 bars of oxygen. The increase of $\mathrm{T}_{\mathrm{g}}$ in air can be attributed to a predominant crosslinking process, but the existence of a minor chain scission process cannot be excluded. It was previously shown that termination between alkyl radicals $\left(\mathrm{P}^{\circ}\right)$ are disfavored under elevated oxygen pressure which suggests that crosslinking must be caused by reactions involving alkyl radicals in termination steps.

Since chain scission phenomena is associated to the formation of carbonyls and amides [12,27], we propose in Fig. 9 to plot $\left(T_{g}-T_{g 0}\right)$ versus the concentration in oxidation products for both epoxy 


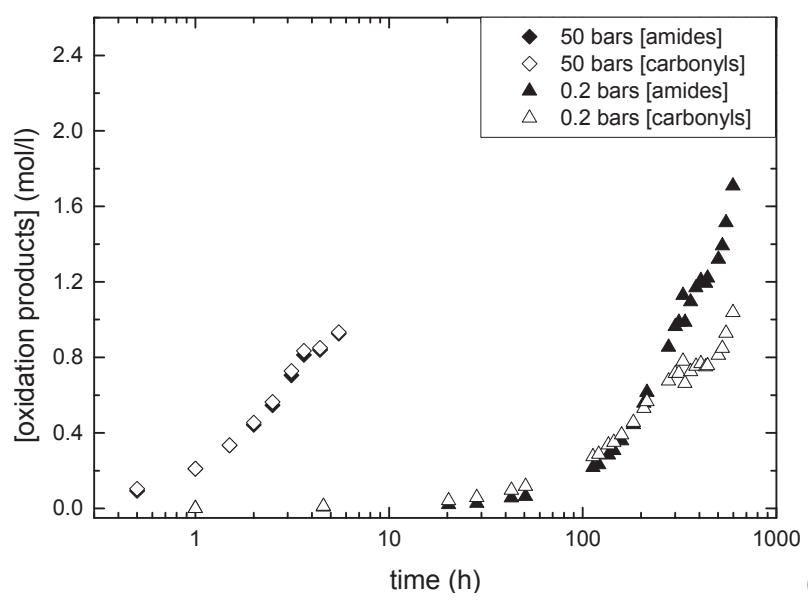

(a)



(b)

Fig. 6. Amides and carbonyls build up for DGEBA/IPDA (a) and DGEBA/TTDA (b) at $110{ }^{\circ} \mathrm{C}$ under 0.2 bars (empty symbol) and under 50 bars (full symbol) of oxygen.

systems at $110{ }^{\circ} \mathrm{C}$ under air and oxygen excess (50 bars).

- In the case of IPDA, the chain scission rate under air is slightly lower than under oxygen excess. It can be explained by the fact that the amount of crosslinking due to alkyl radicals $\left(\mathrm{P}^{\circ}\right)$ recombination is very weak in comparison with the amount of chain scission especially under oxygen excess.

- In the case of TTDA, macromolecular changes depend on oxygen partial pressure as we have seen previously: if the chain scission process is clearly predominant under 50 bars especially at low conversion degree i.e. for carbonyl + amide concentration lower than $0.5 \mathrm{~mol} / \mathrm{l}$, a crosslinking process is then put in evidence for the exposure air condition ( 0.2 bars). In terms of oxidation mechanism, the alkyl $\left(\mathrm{P}^{\circ}\right)$ recombination could not be neglected here especially at low oxygen partial pressure.

In order to investigate the effect of exposure temperature on the mechanism of macromolecular change, $\left(T_{g}-T_{g 0}\right)$ values were also measured for an exposure at $200^{\circ} \mathrm{C}$. At $110^{\circ} \mathrm{C}$, IPDA is oxidized in glassy state and TTDA is oxidized in rubbery state whereas both are in rubbery state at $200^{\circ} \mathrm{C}$. Fig. 10 reports $\left(T_{g}-T_{g 0}\right)$ as a function of carbonyl + amide concentration for both exposure temperatures. It suggests that if crosslinking is slightly favored in rubbery state for DGEBA/IPDA system and possibly by the enhanced macromolecular mobility, $\left(\mathrm{T}_{\mathrm{g}}-\mathrm{T}_{\mathrm{g} 0}\right)$ changes are poorly dependent on exposure temperature. In other words, macromolecular modifications are



(a)



(b)

Fig. 7. Correlation between oxidation products formation for (a) DGEBA/IPDA and (b) DGEBA/TTDA

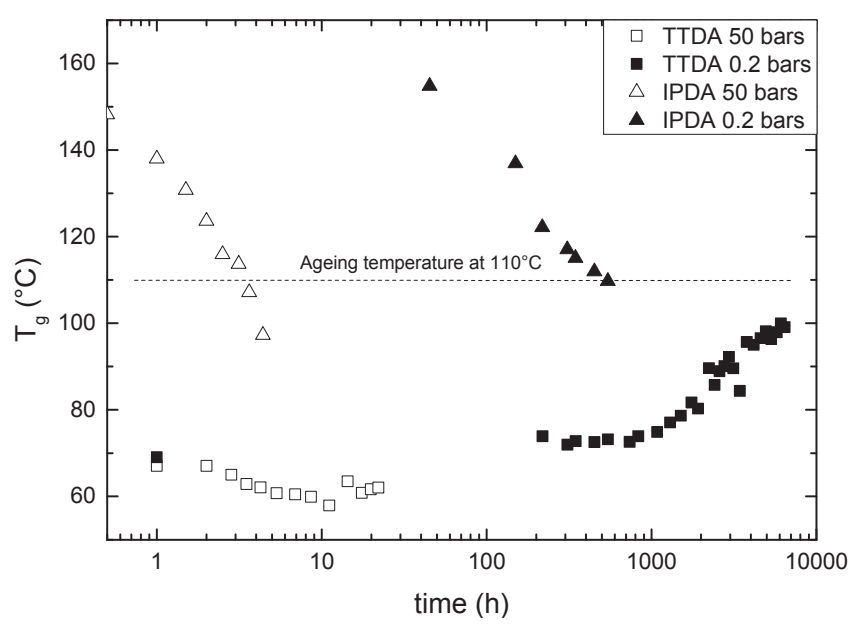

Fig. 8. Glass transition temperature $\left(T_{g}\right)$ changes as a function of time for at $110{ }^{\circ} \mathrm{C}$ under 0.2 and 50 bars oxygen. 




Fig. 9. $T_{g}-T_{g 0}$ with $T_{g 0}$ being initial glass transition temperature, as a function of sum of amides and carbonyls concentration for DGEBA/IPDA and DGEBA/IPDA at $110{ }^{\circ} \mathrm{C}$ under 0.2 bars (empty symbol) and 50 bars of oxygen (full symbol).

hardly driven by the chain mobility (glassy vs rubbery state) in this temperature range.

\section{Discussion}

For us, the most striking results of this study are:

- DGEBA/IPDA system oxidizes faster than DGEBA/TTDA in the whole range of conditions under study.

- DGEBA/IPDA undergoes mainly chain scission which is not systematic for DGEBA/TTDA.

We will try here to interpret those results by discussing the three following points in term of structural characteristics expected to influence the oxidation kinetics:

- Concentration in oxidizable sites (the "Achille's heels" [28]) identified as responsible for the formation of amide and

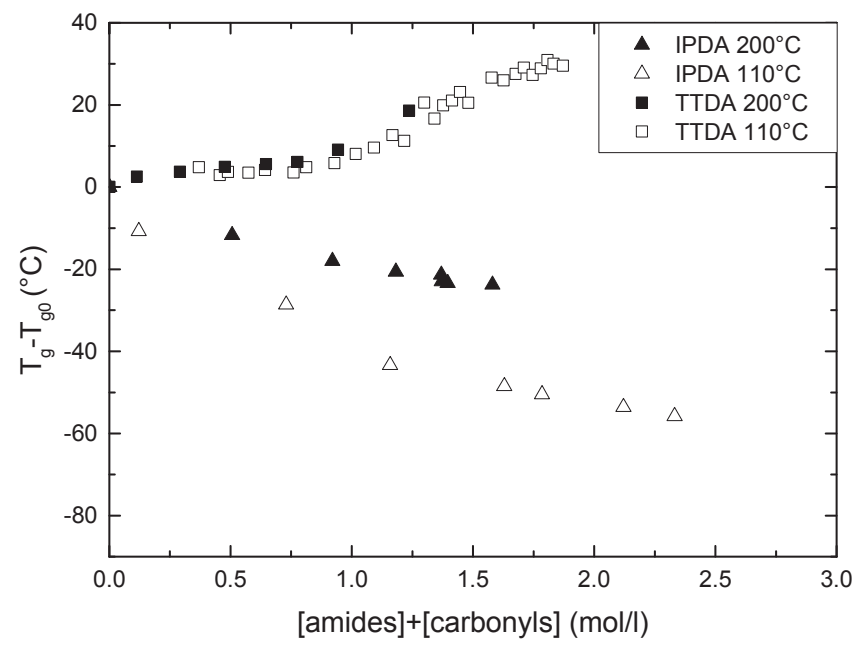

Fig. 10. Changes in glass transition temperature versus the sum of amides and carbonyls concentration for DGEBA/IPDA and DGEBA/TTDA in air at $110{ }^{\circ} \mathrm{C}$ at $110{ }^{\circ} \mathrm{C}$ (empty symbol) and $200{ }^{\circ} \mathrm{C}$ (full symbol). carbonyl groups in order to explain the difference in oxidation rate between both epoxy/hardener systems.

- Influence of macromolecular mobility, which can trigger some bimolecular processes in oxidation especially termination steps [29] and later crosslinking.

- The chemistry of hardener group explaining its sensitivity to oxidation and the existence of specific mechanisms leading to chain scissions or crosslinking.

\subsection{On the concentration in reactive sites in DGEBA/IPDA and DGEBA/TTDA}

Some possible mechanisms for the amides and carbonyls formation are given in Scheme 1.

Let us first assume that the reactivity of each sort of $\mathrm{CH}_{2}$ located respectively in $\alpha$ position of a nitrogen or an oxygen atom are ruled by the same set of rate constants denoted by $\mathrm{k}_{\mathrm{ia}}$ (a stands for amide) and $\mathrm{k}_{\mathrm{ic}}$ (c stands for carbonyl). The rate for amides and carbonyls formation under oxygen excess (e.g. 50 bars $\mathrm{O}_{2}$ ) would be thus given by:

$r_{\text {amide }}=\gamma_{a} \frac{k_{3 a}^{2}}{k_{6 a}}\left[P H_{a}\right]^{2}$

$r_{\text {carbonyl }}=\gamma_{c} \frac{k_{3 c}^{2}}{k_{6 c}}\left[P H_{c}\right]^{2}$

Where $\mathrm{k}_{3}$ denotes the rate constant for propagation $\mathrm{POO}^{\circ}+\mathrm{PH} \rightarrow \mathrm{POOH}+\mathrm{P}^{\circ}$ and $\mathrm{k}_{6}$ for termination $\mathrm{POO}^{\circ}+\mathrm{POO}^{\circ} \rightarrow$ inactive products $\left(\mathrm{P}^{\circ}\right.$ and $\mathrm{POO}^{\circ}$ respectively stand for alkyl and peroxy radical, $\mathrm{POOH}$ for hydroperoxide and $\mathrm{PH}$ for any oxidizable group).

As a result, the difference in rate of amide formation would originate from a difference in concentration of sites $\left[\mathrm{PH}_{\mathrm{a}}\right]$ to generate amides and $\left[\mathrm{PH}_{\mathrm{c}}\right]$ to generate carbonyls.

The concentration of reactive sites likely to generate amides ([ $\left.\left.\mathrm{PH}_{\mathrm{a}}\right]\right)$ or carbonyls $\left(\left[\mathrm{PH}_{\mathrm{c}}\right]\right)$, can be estimated from the structure of a repetitive unit made of 2 DGEBA +1 amide group which can be considered as a "monomer" unit [30]. It contains $4 \mathrm{CH}_{2}$ in $\alpha$ position of nitrogen atom in both cases (DGEBA/IPDA and DGEBA/ TTDA). The molar mass of this "monomer" are respectively equal to $851 \mathrm{~g} / \mathrm{mol}$ for DGEBA/IPDA and $901 \mathrm{~g} / \mathrm{mol}$ for DGEBA/TTDA so that the concentration in reactive site $\left[\mathrm{PH}_{\mathrm{a}}\right]$ are very close in both systems (ca $7 \mathrm{~mol} / \mathrm{kg}$ in DGEBA/IPDA vs 6.6 in DGEBA/TTDA). As a result, oxidation rate $\left(r_{\text {amide }}\right)$ discrepancy between both epoxy systems cannot be attributed to differences in reactive site concentration.

In the case of carbonyls, there are much more possibilities for their formation since each $\mathrm{CH}_{2}$ in $\alpha$ position of an oxygen group are suspected to oxidize to give a carbonyl group responsible for the FTIR absorption centered at $1730 \mathrm{~cm}^{-1}$. Identically than for amides, it can be estimated that the concentration in such $\mathrm{CH}_{2}$ is $9 \mathrm{~mol} / \mathrm{kg}$ in DGEBA/IPDA and $15 \mathrm{~mol} / \mathrm{kg}$ in DGEBA/TTDA. Here also, this is not the right argument to explain why carbonyls appear faster in DGEBA/IPDA than in DGEBA/TTDA.

Last, this simple reasoning, it would be difficult to explain why the values of ratio between amides and carbonyls formation rate are the same in DGEBA/TTDA and DGEBA/IPDA (see Fig. 7).

In conclusion, the fast oxidation of DGEBA/IPDA compared to DGEBA/TTDA cannot be explained from the simple comparison of the relative concentration in reactive sites. Another explanation based on their reactivity (i.e. linked to the relative value of $k_{i}$ ) will be envisaged in the next paragraphs. 


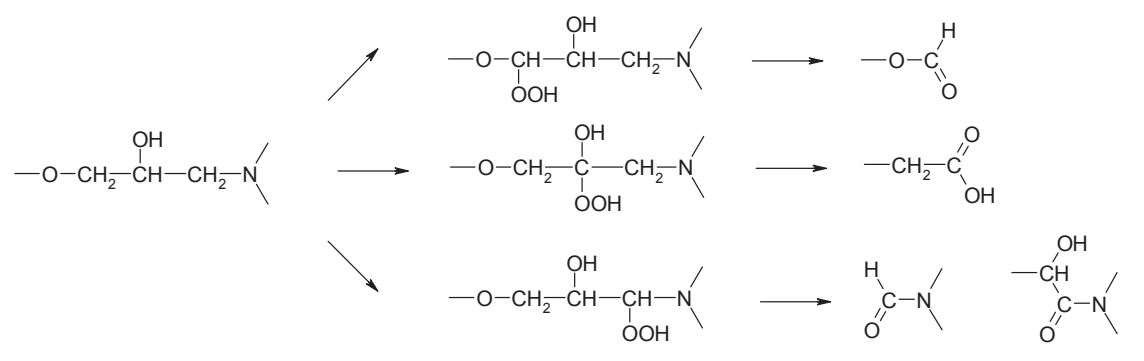

Scheme 1. Formation of oxidation products in epoxy/amine systems.

4.2. On the influence of macromolecular mobility on oxidative stability

Mayo [29] reported the greater oxidizability of bulk PP compared to short hydrocarbons with tertiary carbons, and pointed out the role of macromolecular mobility on the termination rate to explain this behavior. This was later confirmed in the case of epoxy radiolysis [31] where the kinetics of termination between radicals were expressed in function of radicals diffusivity [32] and in another recent work reporting the very low termination rate in a hydrocarbon glassy network [33].

During an exposure at $110{ }^{\circ} \mathrm{C}$, DGEBA/IPDA is in glassy state where radicals would hardly terminate (thus increasing the oxidation rate) whereas DGEBA/TTDA is in rubbery state (i.e. higher mobility and thus higher termination rate) which would explain its greater stability towards oxidation. However, if low macromolecular mobility would actually induce a higher oxidation rate, passing $\mathrm{T}_{\mathrm{g}}$ would induce a change in the oxidation rate ( $\mathrm{r}_{\mathrm{Ox}}$ ) value or at least a change in its apparent activation energy.

An answer comes from plotting the maximal rate for amide formation for both systems under investigation in an Arrhenius diagram together with four other datasets from literature so as to compare epoxy materials differing by their initial $\mathrm{T}_{\mathrm{g}}$ value and aged below and above their glass transition temperature (Fig. 11). (NB: the same was done for carbonyls but is not presented in the aim of conciseness).

According to Fig. 11, there is no breakdown or curvature in the Arrhenius diagram. Apart from a coincidence, it means that all the rate constants, at least $\mathrm{k}_{3}$ (for propagation reaction $\mathrm{POO}^{\circ}+\mathrm{PH} \rightarrow \mathrm{POOH}+\mathrm{P}^{\circ}$ ) and $\mathrm{k}_{6}$ (for the termination reaction $\mathrm{POO}^{\circ}+\mathrm{POO}^{\circ} \rightarrow$ inactive products), obey Arrhenius law i.e. that



Fig. 11. Arrhenius plot of oxidation rate under air of different systems. there is no change in their activation energy when passing $T_{g}(\mathrm{NB}$ : $\mathrm{P}^{\circ}$ and $\mathrm{POO}^{\circ}$ respectively stand for alkyl and peroxy radical, $\mathrm{POOH}$ for hydroperoxide and $\mathrm{PH}$ for any oxidizable group). This first observation militates against the hypothesis of the control by macromolecular mobility.

We tried to confirm this conclusion by an analysis of the apparent activation energy for the termination process. The activation energy for oxidation is given, in a first approach, by:

$\mathrm{E}_{\mathrm{OXi}}=2 \mathrm{E}_{3 \mathrm{i}}-\mathrm{E}_{6 \mathrm{i}}(\mathrm{i}=$ amide or carbonyl $)$

A linear relationship has been proposed by Korcek et al. [35] between the activation energy for propagation changes with the dissociation energy of $\mathrm{C}-\mathrm{H}$ bond:

$\mathrm{E}_{3}=0.55 \times(\mathrm{BDE}(\mathrm{C}-\mathrm{H})-261.5)$

where $\mathrm{E}_{3}$ and $\mathrm{BDE}$ are expressed in $\mathrm{kJ} / \mathrm{mol}$.

Hence, $E_{3}$ does not exceed $60 \mathrm{~kJ} / \mathrm{mol}[24,36]$ so that: $\mathrm{E}_{6}<120-\mathrm{E}_{\mathrm{OXi}}$

The maximal value for $\mathrm{E}_{6}$ estimated from the apparent activation energies for carbonyls and amides formation are systematically lower than $60 \mathrm{~kJ} / \mathrm{mol}$ (Table 2) which is the same order of magnitude than for termination processes for liquid hydrocarbons [37] and significantly lower than the activation energy for processes expected to be controlled by the diffusivity of macromolecular radicals (typically more than $100 \mathrm{~kJ} / \mathrm{mol}$ [38]).

Moreover, it is noteworthy that in the case of DGEBA/IPDA, there are no major changes on the main characteristics of oxidation above $\mathrm{T}_{\mathrm{g}}$ i.e. predominance of chain scission over crosslinking, and faster rate of oxidation products than in DGEBA/TTDA.

To conclude, our analysis of data militates against any explanation based on macromolecular mobility for difference between oxidation kinetics of DGEBA/TTDA and DGEBA/IPDA. A possible explanation is that the $\beta$ transition, which is associated to the isopropanol moiety, induces sufficient mobility for allowing the mobility of radicals [13].

\subsection{On the chemistry of hardeners}

The last possible explanation to interpret the difference between DGEBA/IPDA and DGEBA/TTDA is based on the intrinsic reactivity of hardeners. This might actually explain why:

(1) DGEBA/IPDA undergoes mainly chain scission whereas DGEBA/TTDA undergoes in part some crosslinkings (which may predominate under air).

(2) High proportion of carbonyls compared to amides in DGEBA/ TTDA for exposure under high oxygen pressure (Fig. 7).

In a very simple first approach, the sensitivity to radical oxidation of hardener groups can be evaluated by some physico- 
Table 2

Comparison of mobility dependence of oxidation phenomenon between different systems epoxy/amine.

\begin{tabular}{|c|c|c|c|c|c|c|c|}
\hline & DGEBA/IPDA & DGEBA/TTDA & $\begin{array}{l}\text { DGEBA/polypropylene ether } \\
\text { amine (POPA132) [9] }\end{array}$ & DGEBA/PAA [9] & $\begin{array}{l}\text { DGEBA/polypropylene } \\
\text { ether amine } \\
\text { (POPA230) }[1]\end{array}$ & $\begin{array}{l}\text { DGEBA } \\
\text { /cyclohexylamine [1] }\end{array}$ & DGEBA/PDA [34] \\
\hline $\mathrm{T}_{\mathrm{g}}\left({ }^{\circ} \mathrm{C}\right)$ & 166 & 69 & 75 & 68 & 95 & $150-155$ & Not given \\
\hline Temperature range & $110^{\circ} \mathrm{C}-200{ }^{\circ} \mathrm{C}$ & $110^{\circ} \mathrm{C}-200^{\circ} \mathrm{C}$ & $70-150{ }^{\circ} \mathrm{C}$ & $70-150{ }^{\circ} \mathrm{C}$ & $25-200{ }^{\circ} \mathrm{C}$ & $25-200{ }^{\circ} \mathrm{C}$ & $200-300{ }^{\circ} \mathrm{C}$ \\
\hline $\mathrm{E}_{\mathrm{ox}}(\mathrm{kJ} / \mathrm{mol})$ & 83 & 85 & 56.2 & 55.2 & 75 & 71 & 69.4 \\
\hline $\mathrm{E}_{6}(\mathrm{~kJ} / \mathrm{mol})$ & 34.6 & 33.2 & 61.8 & 62.8 & 43 & 47 & 48.6 \\
\hline
\end{tabular}

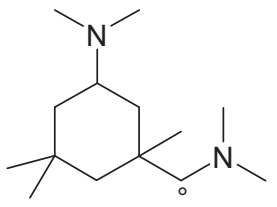

la



$\mathrm{Ib}$
Scheme 2. Possible structure of alkyl radical formed in DGEBA/IPDA.

chemical data such as:

- the bond dissociation energy of $\mathrm{C}-\mathrm{H}$ group suspected to be the weakest point of the hardener group. It seems that the presence of a nitrogen atom in $\alpha$ position of $\mathrm{C}-\mathrm{H}$ is more detrimental to BDE than the presence of an oxygen atom [39,40], and that tertiary $\mathrm{C}-\mathrm{H}$ are weakest than secondary ones so that $\mathrm{C}-\mathrm{H}$ present in IPDA are expected to be more sensitive to radical attack than $\mathrm{C}-\mathrm{H}$ in TTDA.

- the ratio $\mathrm{k}_{3} /\left(2 \mathrm{k}_{6}\right)^{1 / 2}$, where $\mathrm{k}_{3}$ and $\mathrm{k}_{6}$ are respectively the rate constants of the $\mathrm{POO}^{\circ}+\mathrm{PH} \rightarrow \mathrm{POOH}+\mathrm{P}^{\circ}$ propagation and $\mathrm{POO}^{\circ}+\mathrm{POO}^{\circ} \rightarrow$ inactive product termination. It increases with the sensitivity to oxidation. (NB: $\mathrm{P}^{\circ}$ and $\mathrm{POO}^{\circ}$ are respectively alkyl and peroxyl radicals, $\mathrm{PH}$ are the reactive sites of the polymer, $\mathrm{POOH}$ are hydroperoxides).

Those data have not been determined, to our knowledge, for TTDA and IPDA but literature reports some values for model compounds having a certain similarity with hardeners under investigation:
(1) for IPDA:<smiles>CN(C)C1CCCCC1</smiles>

$\mathrm{BDE} \sim 381 \mathrm{~kJ} / \mathrm{mol}[41]$.

$\mathrm{k}_{3} /\left(2 \mathrm{k}_{6}\right)^{1 / 2}=1.05 \times 10^{3} \cdot \exp (-27500 / \mathrm{RT}) \sim 0.186 \mathrm{l}^{1 / 2} / \mathrm{mol}^{1 / 2} / \mathrm{s}^{1 /}$

2 at $110{ }^{\circ} \mathrm{C}[36]$.

(2) for TTDA:<smiles>C1COCCO1</smiles>

$\mathrm{BDE} \sim 400 \mathrm{~kJ} / \mathrm{mol}[34]$

$\mathrm{k}_{3} /\left(2 \mathrm{k}_{6}\right)^{1 / 2}=3.6 \times 10^{4} \cdot \exp (-50400 / \mathrm{RT}) \sim 0.005 \mathrm{l}^{1 / 2} / \mathrm{mol}^{1 / 2} / \mathrm{s}^{1 /}$ 2 at $110{ }^{\circ} \mathrm{C}[42]$.

In other words, part of our results can be explained by the difference in oxidative stability of hardeners groups.

Let's now turn to the degradation route of some radicals located on hardener moiety. IPDA group can produce at least two sorts of alkyl radicals (Scheme 2).<smiles>CN(C)CC1(C)CC(C)(C)CC(O)(CN(C)C)C1</smiles>

Scheme 3. Possible pathways for hydroperoxides decomposition in DGEBA/IPDA. 


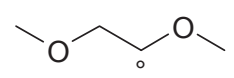

(Ila)

Scheme 4. Possible structure of alkyl radical formed in DGEBA/TTDA

Those radicals will generate a hydroperoxide, the decomposition of which will generate an alkoxy radical $\mathrm{PO}^{\circ}$ (Scheme 3 ).

Product Ic and Ie corresponds well to a chain scission product whereas product Id leads to an increase of the flexibility of the hardener segment and then to a $\mathrm{T}_{\mathrm{g}}$ decrease [26]. In our mind, the crosslinking is unlikely for at least two reasons:

- radicals are particularly hindered and it is difficult to imagine an alkyl coupling reaction ( $\mathrm{P}^{\circ}+\mathrm{P}^{\circ} \rightarrow$ inactive products).

- dialkylperoxides POOP would actually generate a crosslink but they are fairly unstable and would very fast decompose [43].

In TTDA, it is possible that alkyl radicals $\left(\mathrm{P}^{\circ}\right)$ are generated in the vicinity of ethers (Scheme 4).

The high level of carbonyls observed in Fig. 7 would be thus explained as follows: those alkyl radicals will react with oxygen to generate peroxyl radicals $\left(\mathrm{P}^{\circ}+\mathrm{O}_{2} \rightarrow \mathrm{POO}^{\circ}\right)$. Under high oxygen pressure, those later can terminate by a dismutation process leading to several carbonyl species (Scheme 5).

Under air, alkyl radicals $\left(\mathrm{P}^{\circ}\right)$ are expected to participate to termination by coupling thus explaining the existence of a crosslink (Scheme 6). The possibility of an internal coupling (also shown in Fig. 6) involving an increase of the rigidity of the hardener segment (and later its $\mathrm{T}_{\mathrm{g}}$ ) cannot be excluded.

For summarizing, these proposed mechanisms explain why:

- The relatively high steric hindrance makes the coupling very slow in the case of DGEBA/IPDA system compared to DGEBA/

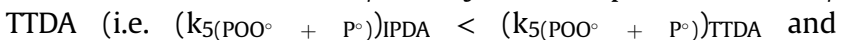

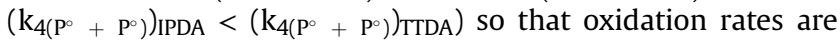
higher for DGEBA/IPDA than DGEBA/TTDA.

- It is more difficult to propose reactions leading to crosslink in DGEBA/IPDA compared to DGEBA/TTDA because the 6 carbon cycle in IPDA is expected to undergo chain scissions whereas TTDA group flexibility explains in part why this hardener leads to crosslink reactions.

In other words, the main trends reported in this paper originate from the specific reactivity of the hardener. The steric hindrance plays a major role as it can be observed in the case of model radicals [44]. It seems obvious that radicals contained in IDPA moiety are less accessible than those contained in TTDA leading to mainly chain scission.

\section{Conclusions}

This paper addresses the case of the thermal oxidative
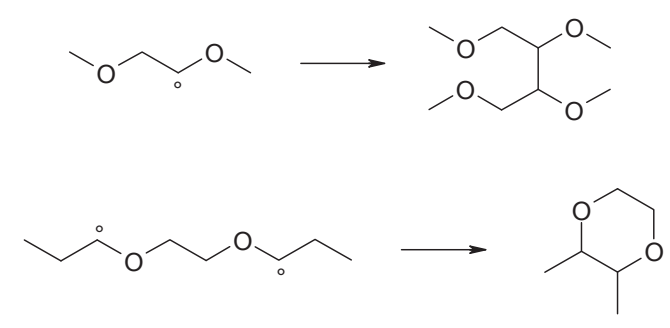

Scheme 6. Termination process by coupling in DGEBA/TTDA.

degradation of two stoichiometric fully cured epoxy-diamine systems based on DGEBA (DER 332) with two different hardeners:

- Isophorone diamine (IPDA) which is highly rigid and leads to a network having a $\mathrm{T}_{\mathrm{g}}$ ca $166^{\circ} \mathrm{C}$.

- 4,7,10-Trioxa-1,13-tridecanediamine (TTDA) which is flexible and leads to a network having a $\mathrm{T}_{\mathrm{g}}$ ca $69{ }^{\circ} \mathrm{C}$.

Appearance of stable oxygenated species was followed by FTIR and chain scissions and/or crosslinking were detected from $\mathrm{T}_{\mathrm{g}}$ changes measured by DSC. The degradation of both systems was shown to generate the same oxidation products i.e. amides and several kinds of carbonyls. In a first approach, the relative proportion of amides over carbonyls is almost the same (amides concentration is about twice the concentration in carbonyls). The rate of formation at several temperatures (from 110 to $200{ }^{\circ} \mathrm{C}$ ) and oxygen pressures (air and 50 bars oxygen) showed DGEBA/IPDA degrades about three times faster than DGEBA/ TTDA. Several reasons were envisaged: the concentration in oxidizable sites located in $\alpha$ position of heteroatoms, the difference in macromolecular mobility expected to influence the kinetics of degradation, and the reactivity of oxidizable sites placed on hardener group, this latter being for us the best explanation.

Both systems also differ in the consequences of oxidation at macromolecular scale: DGEBA/IPDA is a rigid resin where oxidation leads mainly $T_{g}$ depletion associated to chain scissions whereas DGEBA/TTDA was observed to undergo mainly crosslinking. This difference was discussed regarding the possible reaction pathways associated to the hardener part.

Finally, this work illustrates the effect of the hardener nature on the long term performances of epoxies. Despite epoxy/diamine systems have in common the $>\mathrm{N}$-isopropanol group being expected to be the main site for oxidation, it is shown that hardener significantly modifies the kinetics of degradation. This means that any kinetic model dealing with the simulation of oxidation rate has to take into account reactions occurring on the hardener part. It also illustrates the necessity to focus on the consequences of oxidation in terms of chain scissions or crosslinking and the existence of end of life criteria specific to each given epoxy/diamine system.



Scheme 5. Termination process by dismutation in DGEBA/TTDA. 


\section{Acknowledgements}

ANRT (CIFRE $\mathrm{N}^{\circ}$ 2013/0356) is gratefully acknowledged for financial support.

\section{Appendix. Cure of the epoxy diamine system}

\section{Fig. 12 displays:}

- The thermograms of the first heating ramp for an uneacted epoxy + diamine mixture where the curing exotherm is well visible ('thermogram of cure')

- The thermograms of in situ cured epoxy + diamine mixture ("thermogram after cure in situ DSC") obtained after a first heating ramp, where the exothermal signal corresponding to the cure is here no visible anymore. It also shows the glass transition of fully cured networks.

- The thermograms of epoxy + diamine systems cured according to the procedure detailed in the "Experimental" section. It can be observed that the curing exotherm is not visible (total consumption of reactive function) and that the glass transition values are very close to those observed in the thermogram after in situ cure in the DSC.

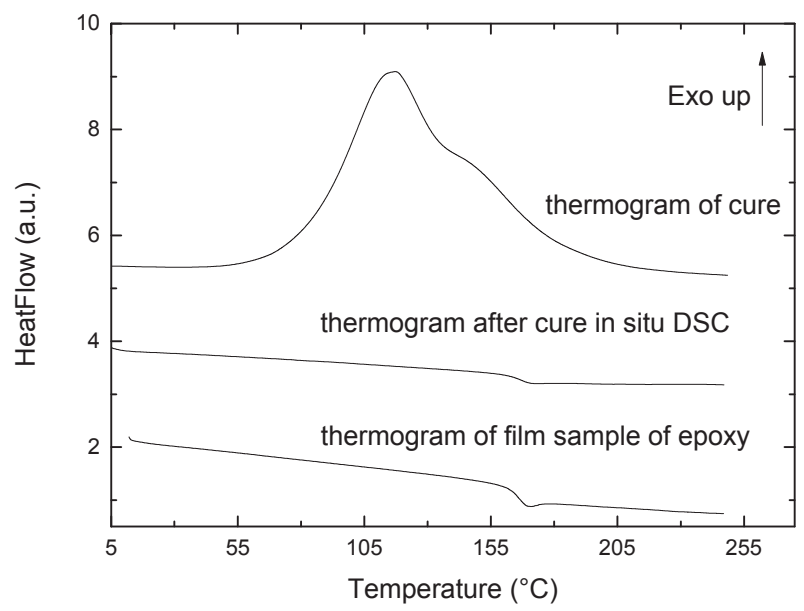

(a)

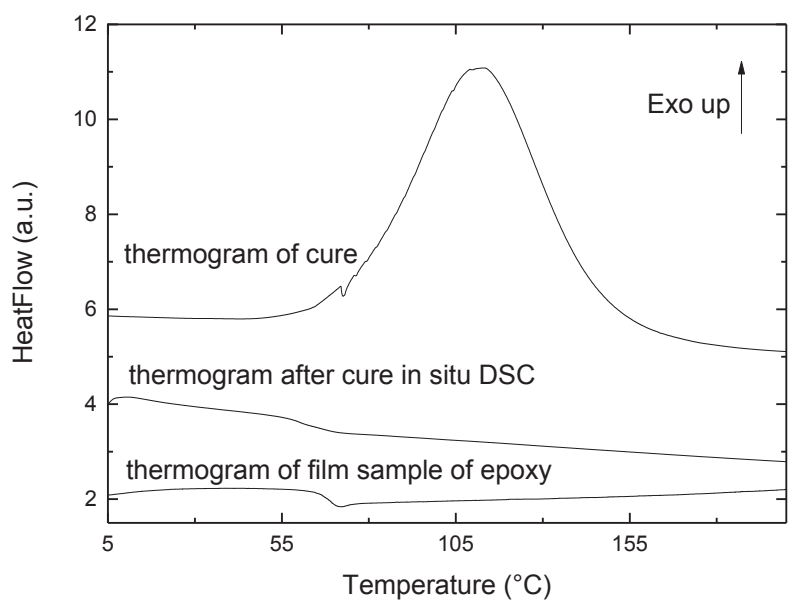

Fig. 12. DSC thermogram of DGEBA/IPDA (a) and DGEBA/TTDA (b) of uneacted expoy + diamine mixture and comparison of thermogram for epoxy cured in situ in the DSC cell and cured according to the procedure detailed in "EXPERIMENTAL SECTION".

\section{References}

[1] M.C. Celina, A.R. Dayile, A. Quintana, A perspective on the inherent oxidation sensitivity of epoxy materials, Polymer 54 (13) (7 June 2013) 3290-3296, http://dx.doi.org/10.1016/j.polymer.2013.04.042.

[2] M. Pecora, Y. Pannier, M.-C. Lafarie-Frenot, M. Gigliotti, C. Guigon, Effect of thermo-oxidation on the failure properties of an epoxy resin, Polym. Test. 52 (July 2016) 209-217, http://dx.doi.org/10.1016/j.polymertesting.2016.04.008.

[3] M. Zhang, B. Sun, B. Gu, Accelerated thermal ageing of epoxy resin and 3-D carbon fiber/epoxy braided composites, Compos. Part A Appl. Sci. Manuf. 85 (June 2016) 163-171, http://dx.doi.org/10.1016/j.compositesa.2016.03.028.

[4] T. Akderya, U. Kemiklioğlu, O. Sayman, Effects of thermal ageing and impact loading on tensile properties of adhesively bonded fibre/epoxy composite joints, Compos. Part B Eng. 95 (15 June 2016) 117-122, http://dx.doi.org/ 10.1016/j.compositesb.2016.03.073.

[5] W. Fan, J.-l. Li, Y.-y. Zheng, T.-j. Liu, X. Tian, R.-j. Sun, Influence of thermooxidative aging on the thermal conductivity of carbon fiber fabric reinforced epoxy composites, Polym. Degrad. Stab. 123 (January 2016) 162-169, http:// dx.doi.org/10.1016/j.polymdegradstab.2015.11.016.

[6] C. Damian, E. Espuche, M. Escoubes, Influence of three ageing types (thermal oxidation, radiochemical and hydrolytic ageing) on the structure and gas transport properties of epoxy-amine networks, Polym. Degrad. Stab. 72 (3) (June 2001) 447-458, http://dx.doi.org/10.1016/S0141-3910(01)00045-3.

[7] J. Decelle, N. Huet, V. Bellenger, Oxidation induced shrinkage for thermally aged epoxy networks, Polym. Degrad. Stab. 81 (2) (2003) 239-248, http:// dx.doi.org/10.1016/S0141-3910(03)00094-6.

[8] X. Colin, C. Marais, J. Verdu, A new method for predicting the thermal oxidation of thermoset matrices: application to an amine crosslinked epoxy, Polym. Test. 20 (7) (2001) 795-803, http://dx.doi.org/10.1016/S01429418(01)00021-6.

[9] Y. Zahra, F. Djouani, B. Fayolle, M. Kuntz, J. Verdu, Thermo-oxidative aging of epoxy coating systems, Prog. Org. Coat. 77 (2) (February 2014) 380-387, http://dx.doi.org/10.1016/j.porgcoat.2013.10.011.

[10] P. Musto, G. Ragosta, P. Russo, L. Mascia, Thermal-oxidative degradation of epoxy and epoxy-bismaleimide networks: kinetics and mechanism, Macromol. Chem. Phys. 202 (18) (December 2001) 3445-3458, http://dx.doi.org/ 10.1002/1521-3935(20011201)202:18<3445::AID-MACP3445>3.0.CO;2-N.

[11] X. Colin, C. Marais, J. Verdu, Kinetic modelling and simulation of gravimetric curves: application to the oxidation of bismaleimide and epoxy resins, Polym. Degrad. Stab. 78 (3) (2002) 545-553, http://dx.doi.org/10.1016/S01413910(02)00230-6.

[12] F. Delor-Jestin, D. Drouin, P.-Y. Cheval, J. Lacoste, Thermal and photochemical ageing of epoxy resin - influence of curing agents, Polym. Degrad. Stab. 91 (6) (June 2006) 1247-1255, http://dx.doi.org/10.1016/ j.polymdegradstab.2005.09.009.

[13] N. Rasoldier, X. Colin, J. Verdu, M. Bocquet, L. Olivier, L. Chocinski-Arnault M.C. Lafarie-Frenot, Model systems for thermo-oxidised epoxy composite matrices, Compos. Part A Appl. Sci. Manuf. 39 (9) (September 2008) 1522-1529, http://dx.doi.org/10.1016/j.compositesa.2008.05.016.

[14] B.J. Anderson, Thermal stability and lifetime estimates of a high temperature epoxy by Tg reduction, Polym. Degrad. Stab. 98 (11) (November 2013) 2375-2382, http://dx.doi.org/10.1016/j.polymdegradstab.2013.08.001.

[15] S. Terekhina, M. Mille, B. Fayolle, X. Colin, Oxidation induced changes in viscoelastic properties of a thermostable epoxy matrix, Polym. Sci. Ser. A 55 (10) (October 2013) 614-624, http://dx.doi.org/10.1134/ S0965545X13090058.

[16] L. Heux, J.L. Halary, F. Lauprêtre, L. Monnerie, Dynamic mechanical and $13 \mathrm{C}$ n.m.r. investigations of molecular motions involved in the $\beta$ relaxation of epoxy networks based on DGEBA and aliphatic amines, Polymer 38 (8) (April 1997) 1767-1778, http://dx.doi.org/10.1016/S0032-3861(96)00694-5.

[17] M. Aufray, Caractérisation physico-chimique des interphases époxydesamine/oxyde ou hydroxyde métallique, et de leurs constituants, Institut national des sciences appliquées Lyon, 2005.

[18] P. Montois, Durabilité de joints collés structuraux époxydes/alliage titane. Application à l'étude d'une interphase modèle, Institut National Polytechnique de Toulouse, 2003.

[19] J. Lacoste, D. Vaillant, D.J. Carlsson, Gamma-, photo-, and thermally-initiated oxidation of isotactic polypropylene, J. Polym. Sci. Part A Polym. Chem. 31 (1993) 715-722, http://dx.doi.org/10.1002/pola.1993.080310316.

[20] K. Li, K. Wang, M. Zhan, W. Xu, The change of thermal-mechanical properties and chemical structure of ambient cured DGEBA/TEPA under accelerated thermo-oxidative aging, Polym. Degrad. Stab. 98 (11) (November 2013) 2340-2346, http://dx.doi.org/10.1016/j.polymdegradstab.2013.08.014.

[21] C. Galant, B. Fayolle, M. Kuntz, J. Verdu, Thermal and radio-oxidation of epoxy coatings, Prog. Org. Coat. 69 (4) (December 2010) 322-329, http://dx.doi.org/ 10.1016/j.porgcoat.2010.07.005.

[22] E. Richaud, F. Farcas, B. Fayolle, L. Audouin, J. Verdu, Hydroperoxide build-up in the thermal oxidation of polypropylene - a kinetic study, Polym. Degrad. Stab. 92 (1) (January 2007) 118-124, http://dx.doi.org/10.1016/ j.polymdegradstab.2006.08.010.

[23] B.J. Anderson, Thermal stability of high temperature epoxy adhesives by thermogravimetric and adhesive strength measurements, Polym. Degrad. Stab. 96 (10) (October 2011) 1874-1881, http://dx.doi.org/10.1016/ j.polymdegradstab.2011.07.010. 
[24] O. Okamba-Diogo, E. Richaud, J. Verdu, F. Fernagut, J. Guilment, B. Fayolle, Molecular and macromolecular structure changes in polyamide 11 during thermal oxidation - kinetic modeling, Polym. Degrad. Stab. 120 (October 2015) 76-87, http://dx.doi.org/10.1016/j.polymdegradstab.2015.06.005.

[25] Y. Zahra, Dégradation de réseaux époxy/amine en ambiance nucléaire, Thèse Arts et Métiers Paristech, 2012.

[26] E. Richaud, F. Farcas, P. Bartoloméo, B. Fayolle, L. Audouin, J. Verdu, Effect of oxygen pressure on the oxidation kinetics of unstabilised polypropylene, Polym. Degrad. Stab. 91 (2) (February 2006) 398-405, http://dx.doi.org/ 10.1016/j.polymdegradstab.2005.04.043.

[27] V. Bellenger, J. Verdu, Oxidative skeleton breaking in epoxy-amine networks, J. Appl. Polym. Sci. 30 (1) (January 1985) 363-374, http://dx.doi.org/10.1002/ app.1985.070300132.

[28] A. Rivaton, L. Moreau, J.-L. Gardette, Photo-oxidation of phenoxy resins at long and short wavelengths-I. Identification of the photoproducts, Polym. Degrad. Stab. 58 (3) (December 1997) 321-332, http://dx.doi.org/10.1016/S01413910(97)00089-X.

[29] F.R. Mayo, Relative reactivities in oxidations of polypropylene and polypropylene models, Macromolecules 11 (5) (1978) 942-946, http://dx.doi.org/ $10.1021 /$ ma60065a020.

[30] V. Bellenger, J. Verdu, E. Morel, Effect of structure on glass transition temperature of amine crosslinked epoxies, J. Polym. Sci. Part B Polym. Phys. 25 (6) (June 1987) 1219-1234, http://dx.doi.org/10.1002/polb.1987.090250604.

[31] T. Devanne, A. Bry, N. Raguin, M. Sebban, P. Palmas, L. Audouin, J. Verdu, Radiochemical ageing of an amine cured epoxy network. Part II: kinetic modelling, Polymer 46 (1) (6 January 2005) 237-241, http://dx.doi.org/ 10.1016/j.polymer.2004.07.041.

[32] T.R. Waite, General theory of bimolecular reaction rates in solids and liquids, J. Chem. Phys. 28 (1) (1958) 103-106, http://dx.doi.org/10.1063/1.1744051.

[33] E. Richaud, P.Y. Le Gac, J. Verdu, Thermooxidative aging of polydicyclopentadiene in glassy state, Polym. Degrad. Stab. 102 (April 2014) 95-104, http://dx.doi.org/10.1016/j.polymdegradstab.2014.01.036.

[34] T. Dyakonov, P.J. Mann, Y. Chen, W.T.K. Stevenson, Thermal analysis of some aromatic amine cured model epoxy resin systems-II: residues of degradation, Polym. Degrad. Stab. 54 (1) (October 1996) 67-83, http://dx.doi.org/ 10.1016/0141-3910(96)00096-1.

[35] S. Korcek, J.H.B. Chenier, J.A. Howard, K. Ingold, Absolute rate constants for hydrocarbon autoxidation. XXI. activation energies for propagation and the correlation of propagation rate constants with carbon-hydrogen bond strengths, Can. J. Chem. 50 (1972) 2285-2297, http://dx.doi.org/10.1139/v72365.

[36] E.T. Denisov, I.B. Afanas'ev, Oxidation and Antioxidants in Organic Chemistry and Biology, Taylor \& Francis, 2005. Table 9.2.

[37] E.T. Denisov, I.B. Afanas'ev, Oxidation and Antioxidants in Organic Chemistry and Biology, Taylor \& Francis, 2005. Table 2.15.

[38] S. Shimada, Y. Hori, H. Kashiwabara, Relation between diffusion controlled decay of radicals and $\alpha$-relaxation in polyethylene and polyoxymethylene Polymer 22 (10) (October 1981) 1377-1384, http://dx.doi.org/10.1016/0032 3861(81)90241-X

[39] T.R. Sharp, Calculated carbon-hydrogen bond dissociation enthalpies for predicting oxidative susceptibility of drug substance molecules, Int. J. Pharm. 418 (2) (14 October 2011) 304-317, http://dx.doi.org/10.1016 j.ijpharm.2011.04.063.

[40] K.R. Przybylak, M.T.D. Cronin, Correlation between bond dissociation energies and spin distribution for the radicals of ethers: a DFT study, J. Mol. Struct. THEOCHEM 955 (1-3) (15 September 2010) 165-170, http://dx.doi.org 10.1016/j.theochem.2010.06.012.

[41] E.T. Denisov, I.B. Afanas'ev, Oxidation and Antioxidants in Organic Chemistry and Biology, Taylor \& Francis, 2005. Table 9.1.

[42] E.T. Denisov, I.B. Afanas'ev, Oxidation and Antioxidants in Organic Chemistry and Biology, Taylor \& Francis, 2005. Table 7.13.

[43] E.G.E. Hawkins, Reactions of organic peroxides. Part XI amino-peroxides from cyclic ketones, J. Chem. Soc. C Org. (20) (1969) 2671-2677, http://dx.doi.org/ 10.1039/J39690002671.

[44] E.T. Denisov, I.B. Afanas'ev, Oxidation and Antioxidants in Organic Chemistry and Biology, Taylor \& Francis, 2005. Table 2.15. 